\title{
Long non-coding RNA SNHG12promotes the proliferation and migration of glioma cells by binding to $\mathrm{HuR}$
}

\author{
WEI LEI ${ }^{1}$, ZHI-LONG WANG ${ }^{2}$, HE-JUN FENG ${ }^{3}$, XIANG-DAN LIN $^{3}$, CHUANG-ZHONG LI $^{1}$ and DI FAN ${ }^{1}$ \\ ${ }^{1}$ Institute of Neurology, General Hospital of Shenyang Military Command, Shengyang, Liaoning 110000; \\ ${ }^{2}$ Graduate School of Dalian Medical University, Dalian, Liaoning 116044; \\ ${ }^{3}$ Graduate School of Jinzhou Medical University, Jinzhou, Liaoning 121001, P.R. China
}

Received March 14, 2018; Accepted June 20, 2018

DOI: $10.3892 /$ ijo.2018.4478

\begin{abstract}
Long non-coding RNAs (lncRNAs) play important roles in biological processes and provide a novel approach with which to understand the molecular mechanisms responsible for glioma. Previous studies have demonstrated that lncRNA small nucleolar RNA host gene 12 (SNHG12) is involved in cell growth and migration. However, the accurate expression pattern of SNHG12 in glioma and the possible associations between this pattern and the clinicopathological characteristics of glioma cohorts are not yet known. The present study investigated the role of IncRNA SNHG12 in the development and progression of glioma, as well as the potential diagnostic value of SNHG12 in patients with glioma. The levels of SNHG12 were detected in resected specimens from patients and in glioma cell lines using reverse transcription-quantitative polymerase chain reaction. The potential effects of SNHG12 on the viability, mobility and apoptosis of glioma cells were evaluated using in vitro assays. The association between SNHG12 and $\mathrm{Hu}$ antigen $\mathrm{R}$ (HuR) was also determined using RNA immunoprecipitation (RIP) and RNA pull-down assays. The results revealed that SNHG12 was significantly upregulated in glioma tissues and cell lines. High levels of SNHG12 were associated with the deterioration of patients with glioma. Patients with high levels of SNHG12 exhibited a reduced 5-year overall survival rate (compared to those with lower levels), particularly in cohorts with high-grade carcinoma (III-IV). The silencing of SNHG12 expression by RNA interference led to a reduced viability and mobility, and in an increased apoptosis of human glioma cells. Furthermore, RIP and RNA pull-down assays demonstrated that SNHG12 was associated with and was stabilized by HuR. The findings of the present study thus identify a novel therapeutic target in glioma.
\end{abstract}

Correspondence to: Professor Di Fan, Institute of Neurology, General Hospital of Shenyang Military Command, 83 Wenhua Road, ShenHe, Shengyang, Liaoning 110000, P.R. China

E-mail: difan1392018@126.com

Key words: SNHG12, glioma, proliferation, invasion, migration, apoptosis, Hu antigen $\mathrm{R}$

\section{Introduction}

According to the World Health Organization (WHO) classification, glioblastoma (GBM), a high grade primary glioma (grade IV), ranks as the most fatal type of glioma in adults. Previous studies have indicated that the present traditional therapy for glioma produces limited curative effects and is unsatisfactory $(1,2)$. Only $10 \%$ of patients with GBM, who are diagnosed with a favorable Karnofsky performance scale (KPS; $>70 \%$ ) and treated with standard therapies live for $>5$ years (3). Therefore, the identification of novel and effective biomarkers may provide more effective therapeutic targets.

In general, a cohort of untranslatable transcripts, known as long non-coding RNAs (IncRNAs) when >200 nucleotides in length, is not responsible for coding proteins. However, they have been demonstrated to be involved in the regulation of gene expression $(4,5)$. An increasing number of studies have demonstrated that lncRNAs are involved in several intracellular biological functions (6,7). Additionally, the abnormal regulation of IncRNAs has been demonstrated to be associated with the deterioration of various types of tumor (8). Small nucleolar RNA host gene 12 (SNHG12), a lncRNA located at chromosome 1p35.3, has primarily been shown to be markedly upregulated in endometrial tumors (9). Furthermore, interference with the expression of SNHG12 in endometrial cancer cells has been shown to inhibit cell proliferation and induce apoptosis (9). A recent study demonstrated that SNHG12 was upregulated and may be an oncogene in various types of human tumors, including osteosarcoma (10), nasopharyngeal carcinoma (11) and lung cancer (12). These studies suggest that SNHG12 plays an important role in the growth, viability, invasion and metastasis of cancer cells. However, to the best of our knowledge, the possible roles of SNHG12 in GBM remain unknown.

As an RNA-binding protein belonging to the ELAV family, $\mathrm{Hu}$ antigen $\mathrm{R}$ (HuR) binds to mRNAs containing adenine (AU)-or uridine (U)-rich sequence elements (ARE) located at the 3'UTR and plays important roles in the post-transcriptional regulation of oncogenes involved in tumorigenesis (13). A previous study demonstrated that the expression of HuR (ELAV1) was elevated in primary brain cancer and maintained the RNA stability of certain growth factors, including vascular endothelial growth factor (VEGF) 
and interleukin (IL)-8 (14). Previous studies have determined the expression of HuR in various types of cancer, including breast (15), colorectal (16), ovarian (17) and pancreatic (18) cancer. Previous studies have also indicated that HuR may be selected as a promising biomarker of certain disease activities (19-24). Filippova et al (14) demonstrated that the regulation of the expression of $\mathrm{HuR}$ by genetic manipulationinduced alterations in the proliferation and the apoptosis of glioma cells, which indicates the potential application of HuR as a promising biomarker and target in glioma. Thus, the present study aimed to investigate the possible roles of SNHG12 involved in the oncogenic events of glioma and the interaction between SNHG12 and HuR in glioma cells.

\section{Materials and methods}

Ethics approval. This study complied with the Declaration of Helsinki and was approved by the Medical Ethics Committee of Biomedicine Research, General Hospital of Shenyang Military Command (Shenyang, China). Glioma tumor specimens were obtained from consenting patients at the General Hospital of Shenyang Military Command (Shenyang, China). The patients were informed and provided written consent.

Sample collection and molecular detection. A total of 79 patients consented to participate in the present study. Between January, 2011 and December, 2012, the patients $(n=79)$ attended the clinic of the General Hospital of Shenyang Military Command. All patients had received surgery at this hospital and had not received any anticancer therapy, including surgical resection, until they were admitted to that hospital. The resected specimens were histopathologically verified as primary glioma on the basis of the WHO Classification of Tumors of the Central Nervous System by three independent senior pathologists $(25,26)$. Primary tumor samples and matched adjacent non-carcinoma tissues were resected for further analysis. The matched adjacent normal tissues were resected $\geq 3 \mathrm{~cm}$ away from the primary carcinoma, as previously described (27).

Molecular feature detection was also performed. Using a DNeasy Blood \& Tissue kit (Qiagen, Tokyo, Japan), DNA was extracted from the frozen cancer tissue according to the manufacturer's instructions. The C228T and C250T mutation hotspots in the TERT promoter, and the presence of isocitrate dehydrogenase (IDH) gene 1 (R132) and 2 (R172) hotspot mutations, were assessed by pyrosequencing and partly by Sanger sequencing, as previously described $(28,29)$. The methylation status of the $M G M T$ promoter was also detectedusing a customized pyrosequencing assay, as previously reported (30).

Cell culture and transfection. The normal human skin fibroblast HF cell line and the glioma cell lines, U87, LN229, U373 and U251, were purchased from the Cell Bank of the Chinese Academy of Sciences (Shanghai, China). It should be noted that the cell line U373 has been reported to be misidentified according to the Cellosaurus (https://web.expasy.org/cellosaurus/CVCL_2219). Therefore, the identity of the cell line used in the present study was validated via an STR profile test by the Cell Bank of the Chinese Academy of Sciences. The results revealed that the matching ratio between the test sample and ATTC standard data was $88.8 \%$, which indicates that the cell line used in the present study is identifiable as U373 according to the ASN-0002-2011 criterion. The U87 cell line has also been reported to be misidentified/contaminated and this cell line is considered glioblastoma of unknown origin. The U87 cell line was also authenticated using an STR profile test by the Cell Bank of the Chinese Academy of Sciences. The results revealed that the matching ratio between the test sample and ATTC standard data was $94.4 \%$ and confirmed the identity of the cell line used in this study as U87. Dulbecco's modified Eagle's medium (Gibco/Thermo Fisher Scientific, Shanghai, China), supplemented with $10 \%$ fetal bovine serum as well as $100 \mathrm{U} / \mathrm{ml}$ penicillin and $100 \mu \mathrm{g} / \mathrm{ml}$ streptomycin (Biowest, Nuaillé, France) were employed for cell culture (31).

Specific small interfering RNAs (siRNA) targeting human SNHG12 mRNA (si-SNHG12) were designated and purchased from Sangon Biotech Co., Ltd. (Shanghai, China). The sequences were as follows: Sense, 5'-GCAGUGUGCUAC UGAACUUTT-3' and antisense, 5'-AAGUUCAGUAGCACA CUGCTT-3' (32). Using Lipofectamine 2000 reagent (Invitrogen, Carlsbad, CA, USA), $2 \times 10^{5} \mathrm{HF}$, U87 and U251 cells were prepared and transfected for $48 \mathrm{~h}$, respectively. The negative control duplex containing siRNA (si-NC; Sangon Biotech Co., Ltd.) was employed as the control.

For SNHG12 overexpression, the full-length SNHG12 cDNA was synthesized by Biomarker Technologies (Beijing, China) and bound with the pcDNA3.1(+) vector (Invitrogen), as previously described $(31,32)$. PcDNA3.1-SNHG12 (p-SNHG12) and control blank vector ( $\mathrm{p}-\mathrm{NC}$ ) were transfected into the U87 and U251 cells using Lipofectamine 2000 reagent. As the normal control, HF cells were also prepared for transfection with p-SNHG12 or p-NC. The cells were collected for reverse transcription-quantitative polymerase chain reaction (RT-qPCR) analysis at $48 \mathrm{~h}$ after transfection.

The expression of HuR in the U87 and U251 cells was upregulated or specifically downregulated in order to determine whether SNHG12 is associated with HuR, as previously described (33). Briefly,the pMSCV-PIG plasmidligated intoHuRDNAfragments (CMV-HuR) and pMDH-PGK-EGFP2.0 vector inserted with HuR siRNA (si-HuR) were prepared. The HuR siRNA sequence was as follows: 5'-UUGUCAAACCGGAUAAACGCA-3'. The levels of SNHG12 in the U87 and U251 cells, transfected with $\mathrm{CMV}-\mathrm{HuR} /$ control vector or si-HuR/negative control (si-NC) were detected by using RT-qPCR.

$R T-q P C R$. The expression of SNHG12 in the human glioma cells or specimens from patients with glioma was evaluated by RT-qPCR as previously described (32). Briefly, TRIzol reagent was used for total RNA extraction. The extracted RNA was then reverse transcribed into cDNA using the ProtoScript ${ }^{\circledR}$ First Strand cDNA Synthesis kit (New England Biolabs, Ipswich, MA, USA) according to the manufacturer's instructions. iQ SYBR Green Supermix (Bio-Rad, Hercules, CA, USA) was employed for RT-qPCR analysis according to the manufacturer's instructions. The $2^{-\Delta \Delta C t}$ or $2^{-\Delta \Delta C q}$ method (33) was performed to analyze the relative changes of SNHG12 after normalizing to GAPDH (endogenous control). The primer sequences were as follows: GAPDH sense, 5'-CGAGATCCCTCCAAAATCAA-3' and antisense, 5'-TTCACACCCATGACGAACAT-3'; SNHG12 sense, 5'-TCTGGTGATCGAGGACTTCC-3' and antisense, 
5'-ACCTCCTCAGTATCACACACT-3' (32); HuR sense, 5'-ATG AAGACCACATGGCCGAAGACT-3' and antisense, 5'-TGT GGTCATGAGTCCTTCCACGAT-3' (34).

Cell viability assay. Following various treatments, cell viability was evaluated by MTT assay as previously described (31). Briefly, $1 \times 10^{5}$ cells $/ \mathrm{ml}$ were seeded into culture plates with $200 \mu \mathrm{l}$ culture medium per well. After $48 \mathrm{~h}$, the cells were incubated with $20 \mu \mathrm{l}$ of $5 \mathrm{mg} / \mathrm{ml}$ MTT solution at $37^{\circ} \mathrm{C}$ for $4 \mathrm{~h}$, followed by the addition of $150 \mu \mathrm{l}$ dimethyl sulfoxide. A microplate reader (Multiskan Mk3; Thermo Fisher Scientific) was used to measure the absorbance of each sample at $570 \mathrm{~nm}$ and the data were collected for analysis.

Migration and invasion assays. Migration and invasion assays were performed as previously described (35). Cells at a density of $1 \times 10^{5} / \mathrm{ml}$ were prepared in serum-free medium and plated in the upper chamber for the cell migration assay. Achamber pre-coated with $500 \mathrm{ng} / \mathrm{ml}$ Matrigel solution (BD Biosciences, Franklin Lakes, NJ, USA) was obtained for the cell invasion assay. Cells that had migrated to the upper membrane surface were physically removed after $48 \mathrm{~h}$ of incubation. Those that had migrated or invaded to the lower side of the membrane were collected for statistical analysis. The cells were then fixed, stained and imaged under a microscope as previously described (36).

Scratch wound assay. A scratch wound assay was performed to evaluate the migration of glioma cells after the various treatments, as previously described (37). Briefly, at 80\% confluency, the cells transfected with various chemicals were seeded onto 6-well plates and incubated at $37^{\circ} \mathrm{C}$, respectively. Using a $10-\mu 1$ pipette tip, a vertical scratch wound was made through the center of each well plate. After washing 3 times with PBS, fresh serum-free medium was added and the cells were incubated for $48 \mathrm{~h}$. Subsequently, a light microscope (Olympus, Tokyo, Japan) was used to examine the mobility of the cell monolayer at a magnification of $\times 200$.

Apoptosis assay. Flow cytometric analysis was performed to evaluate the effects of SNHG12 on the apoptosis of the cells, by transfecting the U87 and U251 cells with either si-SNHG12 or p-SNHG12. An Annexin V-fluorescein isothiocyanate (FITC), propidium iodide (PI) assay kit (4A Biotech Co., Ltd.), FACScan flow cytometer and Cell Quest software (both from BD Immunocytometry Systems, San Jose, CA, USA) were employed to determine the rates of cell apoptosis.

Bioinformatics analysis. A total of 118,777 transcripts were obtained from LNCipedia (www.lncipedia.org)as previously described (34). As HuR directly binds to mRNA at $3^{\prime}$ UTR containing ARE elements, transcripts containing ARE elements were selected as the potential targets for HuR.

RNA immunoprecipitation (RIP) assay. Using the Magna RIP kit (Millipore, Billerica, MA, USA), RIP assay was performed according to the manufacturer's instructions. Briefly, at 80-90\% confluency, the U87 and U251 cells were collected and lysed in RIP lysis buffer. The cell extract $(100 \mu \mathrm{l})$ was prepared and incubated with RIP buffer pre-conjugated with HuR antibodies (1.5 $\mu \mathrm{g}$ per $500 \mu \mathrm{g}$ of total protein; cat. no. sc-5261; Santa Cruz Biotechnology, Santa Cruz, CA, USA) or control mouse $\mathrm{IgG}$ (cat. no. HP6069, Millipore) at $4^{\circ} \mathrm{C}$ for $4 \mathrm{~h}$. The complexes were treated with Proteinase K for $30 \mathrm{~min}$ with shaking at $55^{\circ} \mathrm{C}$. Immunoprecipitated RNA in the precipitates was purified using TRIzol RNA reagent (Invitrogen) and analyzed for SNHG12 by RT-qPCR.

RNA pull-down assays. The interaction between SNHG12 and HuR was further determined by an RNA pull-down assay as previously described (31). The pCDNA3.1-SNHG12 vector was cleaved by $\mathrm{NruI}$ and incubated with RNase-free DNaseI (Takara, Dalian, China). The mMESSAGE mMACHINE T $7^{\circledR}$ kit (Ambion/Thermo Fisher Scientific) was used to transcribe SNHG12 from the pCDNA3.1-SNHG12 vector. The transcribed SNHG12 was then purified using a RNeasy Mini kit (Qiagen, Valencia, CA, USA). A Pierce RNA 3' End Desthiobiotinylation kit (Thermo Fisher Scientific) was employed to label the 3 ' end of SNHG12 as per the instructions provided with the kit. The non-specific IgG antibody was used as the negative control. The binding protein isolated from the RNA-protein complex was then determined by western blot analysis.

Western blot analysis. Total proteins were extracted from the cells with various treatments using cell lysis buffer for western blot analysis (Beyotime Biotechnology, Shanghai, China). The concentration of protein wasthen detected using the BCA Assay kit (Beyotime Biotechnology) according to the manufacturer's instructions. The expression of HuR protein was detected as previously described (34). Briefly, cell lysates were prepared with RIPA lysis buffer containing protease inhibitor cocktail (both from Beyotime Biotechnology). The nitrocellulose membranes on which the protein samples were transferred to were blocked for $2 \mathrm{~h}$ at room temperature and then incubated overnight at $4{ }^{\circ} \mathrm{C}$ with the primary antibodies, including HuR (dilution 1:800; cat. no. sc-5261) and GAPDH (dilution 1:1500; cat. no. sc-47724) (both from Santa Cruz Biotechnology). After washing, the membranes were incubated with horseradish peroxidase-conjugated secondary antibody (dilution 1:1,000; no. A0216; Beyotime Biotechnology) for $1 \mathrm{~h}$. Protein blots were determined using enhanced chemiluminescence luminol reagent (Millipore) and quantified by densitometric analysis using Quantity One software (Bio-Rad).

Statistical analysis. Data are presented as the means \pm standard deviation. SPSS software version 19.0 (SPSS Inc., Chicago, IL, USA) was employed for analyses. The association between SNHG12 levels (low or high level) and the clinicopathological or genetic characteristics of the patients with glioma was evaluated using multivariate logistic regression analysis. Odds ratio (OR) with $95 \%$ confidence interval (CI) were employed to evaluate the strength of association. Ordinal data were collected and analyzed using logistic regression. Survival curves were estimated with the Kaplan-Meier method, and differences were compared using the log-rank test. The statistical significance of SNHG12 expression, MTT cell activity, migration, invasion and apoptosis rate among groups with different treatments was analyzed by one-way ANOVA. A least significant difference post hoc test by 
Table I. Association of SNHG12 expression is with the clinicopathological characteristics of patients with glioma.

\begin{tabular}{|c|c|c|c|c|c|}
\hline \multirow[b]{2}{*}{ Parameters } & \multicolumn{2}{|c|}{ SNHG12 expression, n (\%) } & \multirow[b]{2}{*}{$\mathrm{r}_{\mathrm{s}}$} & \multirow[b]{2}{*}{ P-value } & \multirow[b]{2}{*}{$\begin{array}{l}\text { Adjusted OR } \\
(95 \% \mathrm{CI})\end{array}$} \\
\hline & $\begin{array}{c}\text { Low level } \\
n=40\end{array}$ & $\begin{array}{c}\text { High level } \\
n=39\end{array}$ & & & \\
\hline Ages (years) & & & 0.176 & 0.021 & \\
\hline$<55$ & $28(35.4)$ & $14(17.7)$ & & & $0.42(0.23-0.83)$ \\
\hline$\geq 55$ & $12(15.2)$ & $25(31.7)$ & & & $5.21(2.67-10.79)$ \\
\hline Sex & & & 0.007 & 0.671 & \\
\hline Male & $21(26.5)$ & $19(24.1)$ & & & $1.23(0.46-2.17)$ \\
\hline Female & $19(24.05)$ & $20(25.3)$ & & & $1.03(0.52-2.95)$ \\
\hline Resection status & & & 0.009 & 0.572 & \\
\hline Total & $17(21.5)$ & $21(26.6)$ & & & $1.34(0.67-2.09)$ \\
\hline Subtotal & $23(29.1)$ & $18(22.8)$ & & & $1.19(0.54-4.13)$ \\
\hline Tumor size (cm) & & & 0.069 & 0.108 & \\
\hline$<5$ & $22(27.84)$ & $16(20.3)$ & & & $1.21(0.75-3.46)$ \\
\hline$\geq 5$ & $18(22.8)$ & $23(29.1)$ & & & $1.42(0.63-1.69)$ \\
\hline Tumor location & & & 0.014 & 0.595 & \\
\hline Frontal & $15(19)$ & $14(17.7)$ & & & $1.12(0.89-2.25)$ \\
\hline Occipital & $5(6.3)$ & $5(6.3)$ & & & $1.02(0.93-1.13)$ \\
\hline Temporal & $7(8.9)$ & $8(10.1)$ & & & $1.24(0.82-3.33)$ \\
\hline Other & $13(16.5)$ & $12(15.2)$ & & & $1.08(0.69-2.21)$ \\
\hline WHO grade & & & 0.349 & 0.003 & \\
\hline Low grade (I-II) & $31(39.2)$ & $10(12.7)$ & & & $0.43(0.24-0.88)$ \\
\hline High grade (III-IV) & $9(11.4)$ & $29(36.7)$ & & & $4.54(2.09-9.97)$ \\
\hline Number of tumor nodules & & & 0.009 & 0.705 & \\
\hline Multiple & $2(2.5)$ & $3(3.8)$ & & & $1.04(0.76-3.57)$ \\
\hline Single & $38(48.1)$ & $36(45.6)$ & & & $1.21(0.76-2.86)$ \\
\hline KPS score & & & 0.498 & 0.001 & \\
\hline$<80$ & $11(13.9)$ & $31(39.3)$ & & & $5.07(2.93-8.02)$ \\
\hline$\geq 80$ & $29(36.7)$ & $8(10.1)$ & & & $0.67(0.39-0.78)$ \\
\hline
\end{tabular}

Values in bold indicate statistical significance $(\mathrm{P}<0.05)$. SNHG12, long non-coding RNA small nucleolar RNA host gene 12; KPS score, Karnofsky performance score; OR, odds ratio; CI, confidence interval.

Student-Newman-Keuls test was used to obtain individual P-values following ANOVA, as previously described (31). $\mathrm{P} \leq 0.05$ was considered to indicate a statistically significant difference.

\section{Results}

SNHG12 expression is elevated in glioma tissues and cells. The results of RT-qPCR analysis revealed that the expression levels of SNHG12 were prominently increased in the glioma tissues compared with those of the matched non-cancerous brain tissues $(\mathrm{P}<0.05)$ (Fig. 1A). The SNHG12 level were also increased in all the human glioma cell lines (U87, LN229, U373 and U251) compared to the HF cells, respectively $(\mathrm{P}<0.05)$ (Fig. 1B).

Increased SNHG12 expression is associated with glioma progression. According to the SNHG12 level (determined by
RT-qPCR), the patients enrolled in the present study were divided into 2 groups as follows: Those with less than or equal to the median of the SNHG12 levels (low level) and those with higher than the median of the SNHG12 levels (high level). The associations between the clinicopathological characteristics of the patients with glioma and the SNHG12 mRNA levels were analyzed. The data demonstrated that high levels of SNHG12 were significantly associated with age ( $\mathrm{r}=0.176, \mathrm{P}=0.021)$, WHO grade $(\mathrm{r}=0.349, \mathrm{P}=0.003)$ and $\mathrm{KPS}$ score $(\mathrm{r}=0.498$, $\mathrm{P}=0.001$ ) (Table I). Sex, resection status, tumor size and tumor location were not found to be associated with SNHG12 expression (Table I).

The assessment of the molecular characteristics of these unselected patients with glioma was also performed. The data revealed that SNHG12 expression was significantly associated with TERT promoter mutation ( $\mathrm{r}=0.448, \mathrm{P}=0.001), I D H 1$ mutation $(\mathrm{r}=0.609, \mathrm{P}=0.0007), 1 p / 19 q$ status $(\mathrm{r}=0.712, \mathrm{P}=0.0005)$ and MGMT methylated status ( $\mathrm{r}=0.401, \mathrm{P}=0.002)$ (Table II). 
A

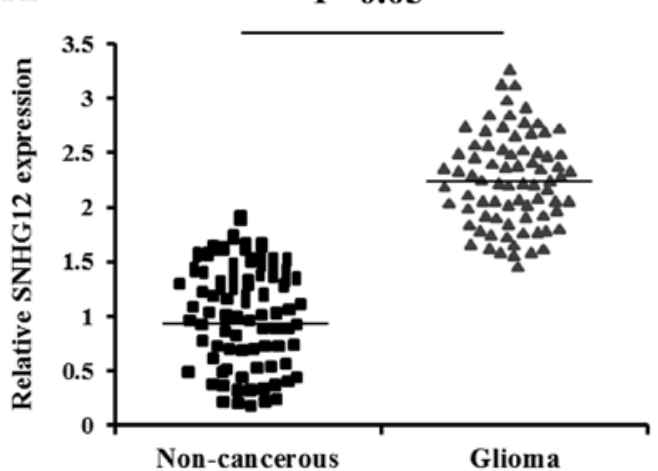

B

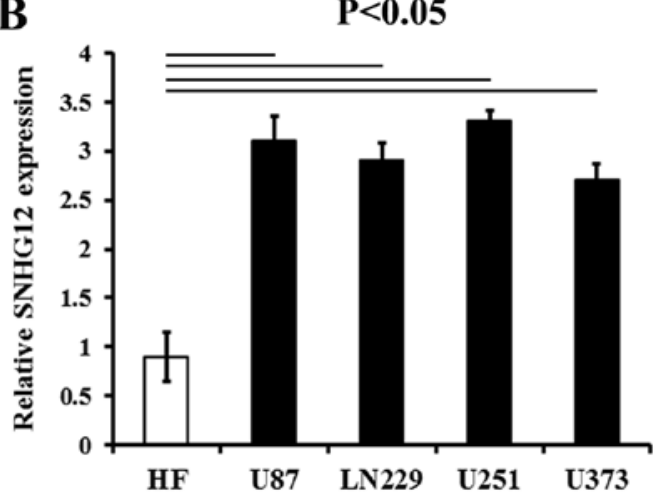

Figure 1. SNHG12 expression is elevated in glioma tissue and cells. (A) Relative expression of SNHG12 in adjacent non-cancerous tissues and glioma tumors was examined by RT-qPCR (n=79). (B) Relative expression of SNHG12 in the normal human HF cell line and the glioma cell lines, U87, LN229, U251 and U373. Data are presented as the means \pm standard deviation. Five independent experiments were performed 7 times $(n=7)$. SNHG12, small nucleolarRNAhost gene 12; RT-qPCR, reverse transcription-quantitative polymerase chain reaction.
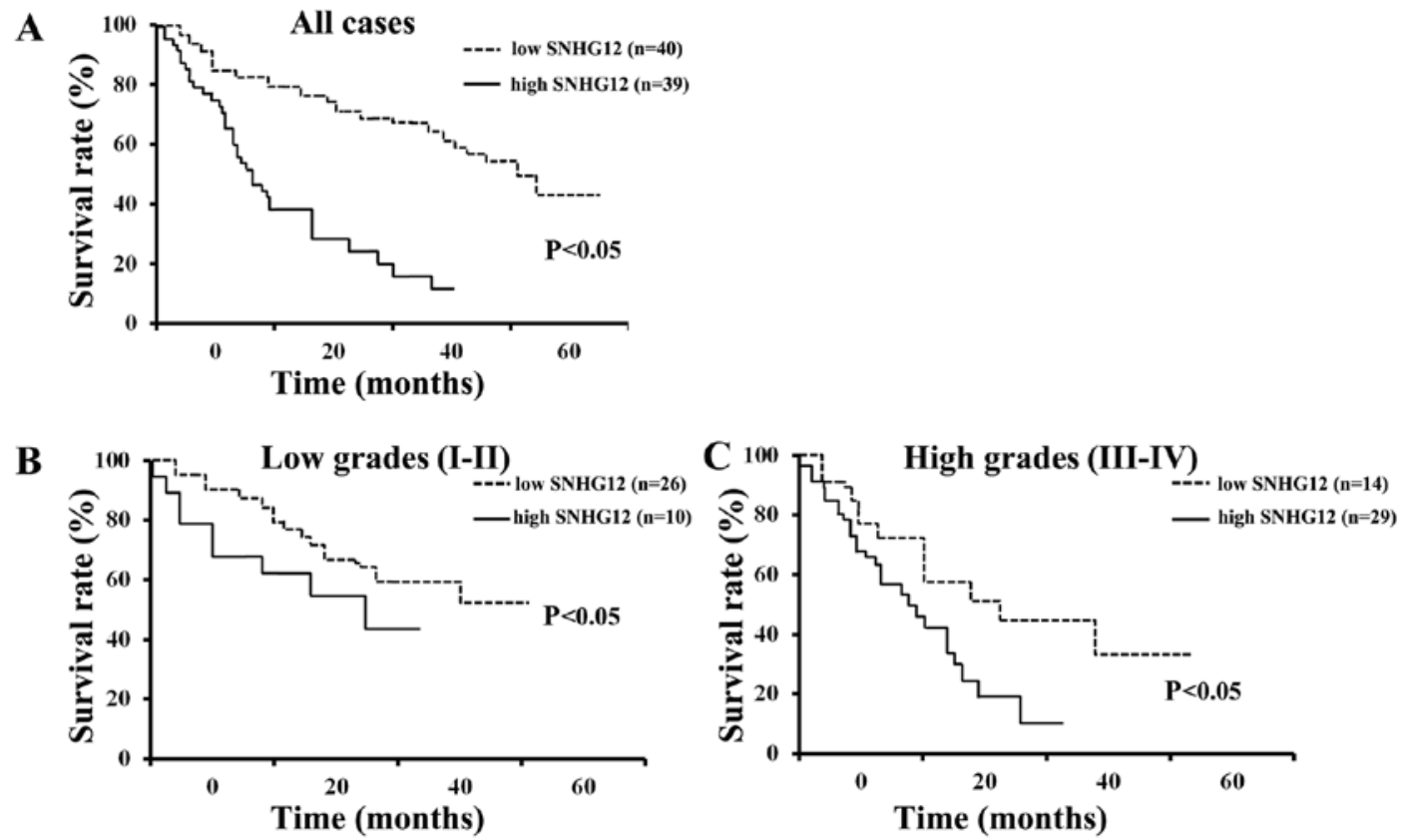

Figure 2. Low levels of SNHG12 are associated with increased OS of patients with glioma. (A) Five-year OS rates of patients with glioma and different levels of SNHG12 by Kaplan-Meier survival analysis (all cases). (B) Kaplan-Meier OS curve analyses of SNHG12 levels in glioma by WHO grade (I-II). (C) Kaplan-Meier OS curve analyses of SNHG12 levels in glioma by WHO grade (III-IV). SNHG12, small nucleolar RNA host gene 12; OS, overall survival.

Kaplan-Meier survival analysis revealed that the patients with low levels of SNHG12 had a significantly increased overall survival (OS) compared to those with high levels of SNHG12 expression $(\mathrm{P}<0.05)($ Fig. 2A). The data also indicated that patients with either low grade (I-II) or high grade (III-IV) glioma and low levels of SNHG12 expression had an increased OS, compared to those with high levels of SNHG12 expression $(\mathrm{P}<0.05)$ (Fig. 2B and C). These results indicate that the SNHG12 level is a promising indicator for patients with glioma of all WHO grades, particularly in those with grade III-IV glioma.

SNHG12 expression following transfection with SNHG12 siRNA or overexpression plasmid. The expression of SNHG12 in the HF cells and glioma cell lines transfected with si-SNHG12, p-SNHG12 or the matched control si-NC, p-NC, was determined by RT-qPCR. The data revealed a significant decrease $(>77 \%)$ in SNHG12 mRNA expression following stable transfection of the U87, U251 and HF cells with si-SNHG12 in (Fig. 3A). Following p-SNHG12 transfection, the SNHG12 levels were markedly higher than those in the matched p-NC-treated ones, respectively $(\mathrm{P}<0.05)$ (Fig. 3B). The expression levels of SNHG12 increased 2.8-fold in the HF cells, 2.5-fold in the U87 cells and 1.9-fold in the U251 cells, compared to the matched $\mathrm{p}-\mathrm{NC}$-treated cells, respectively.

SNHG12 increases the viability and mobility of glioma cells. The functional inhibition of endogenous SNHG12 significantly decreased the viability of both the U87 and U251 cells (compared to the matched si-NC-treated ones, respectively) $(\mathrm{P}<0.05)$ (Fig. 4A). Conversely, transfection with SNHG12 by specific p-SNHG12 induced a significant promotion of the viability of both the U87 and U251 cells $(\mathrm{P}<0.05)$ (Fig. 4A). 
Table II. Association between SNHG12 expression and molecular characteristics of patients with glioma.

\begin{tabular}{|c|c|c|c|c|c|}
\hline & \multicolumn{2}{|c|}{ SNHG12 expression, n (\%) } & \multirow[b]{2}{*}{$\mathrm{r}_{\mathrm{s}}$} & \multirow[b]{2}{*}{ P-value } & \multirow[b]{2}{*}{$\begin{array}{l}\text { Adjusted OR } \\
\quad(95 \% \mathrm{CI})\end{array}$} \\
\hline & $\begin{array}{c}\text { Low level } \\
n=40\end{array}$ & $\begin{array}{c}\text { High level } \\
n=39\end{array}$ & & & \\
\hline TERT status & & & 0.448 & 0.001 & \\
\hline WT & $29(36.7)$ & $13(16.5)$ & & & $0.31(0.22-0.65)$ \\
\hline mut & $11(13.9)$ & $26(32.9)$ & & & $5.23(3.09-11.28)$ \\
\hline IDHI/2 status & & & 0.609 & 0.0007 & \\
\hline WT & $10(12.7)$ & $28(35.4)$ & & & $4.75(6.98-15.76)$ \\
\hline mut & $30(38)$ & $11(13.9)$ & & & $0.36(0.18-0.79)$ \\
\hline $1 p / 19 q$ status & & & 0.712 & 0.0005 & \\
\hline Non-codel & $35(44.3)$ & $7(8.9)$ & & & $0.21(0.13-0.58)$ \\
\hline Codel & $5(6.3)$ & $32(40.5)$ & & & $6.73(3.49-10.96)$ \\
\hline$M G M T$ status & & & 0.401 & 0.002 & \\
\hline Methylation & $12(15.2)$ & $27(34.2)$ & & & $5.54(2.33-11.64)$ \\
\hline Unmethylation & $28(35.4)$ & $12(15.2)$ & & & $0.44(0.29-0.79)$ \\
\hline
\end{tabular}

Values in bold indicate statistical significance $(\mathrm{P}<0.05)$. WT, wild-type; mut, mutation; $1 \mathrm{p} / 19 \mathrm{q}$ codel, co-deletions of chromosome $1 p / 19 q$; TERT, telomerase reverse transcriptase; OR, odds ratio; CI, confidence interval.
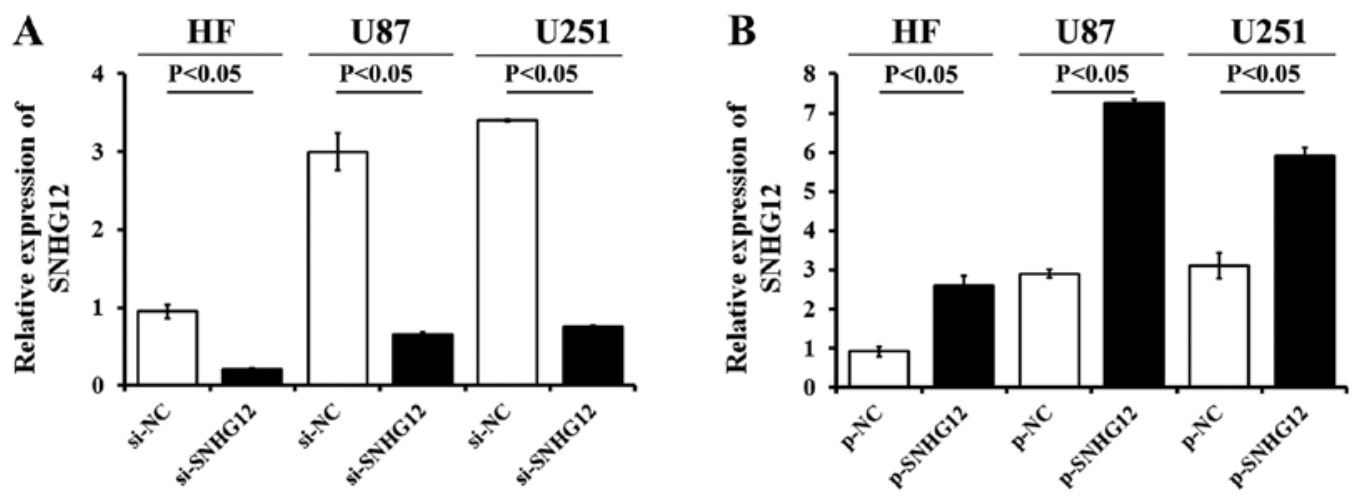

Figure 3. Relative expression of SNHG12 following transfection with siRNA and or overexpression plasmid. (A) SNHG12 levels in HF, U87 and U251 cells following si-SNHG12 transfection were determined by RT-qPCR. (B) SNHG12 levels in HF, U87 and U251 cells following SNHG12 overexpression plasmid transfection were detected by RT-qPCR. Data are presented as the means \pm standard deviation. All data are representative of 7 independent experiments $(\mathrm{n}=7)$. si-NC, SNHG12 siRNA negative control; si-SNHG12, SNHG12 siRNA; p-NC, blank plasmid served as control; p-SNHG12, pcDNA3.1-SNHG12; SNHG12, small nucleolarRNAhost gene 12; siRNA, small interfering RNA; RT-qPCR, reverse transcription-quantitative polymerase chain reaction.

As shown by results of the migration and invasion assays, there were less stained cells observed in the si-SNHG12-transfected group than that in the matched si-NC control groups $(\mathrm{P}<0.05)$ (Fig. 4B and C). Transfection with p-SNHG12 increased the levels of migration and invasion in both the glioma cell lines compared to the $\mathrm{p}-\mathrm{NC}$-treated cells $(\mathrm{P}<0.05)$ (Fig. 4B and $\mathrm{C})$. Scratch wound assay revealed that transfection with si-SNHG12 significantly impaired the invasiveness of the U87 and U251 cells (Fig. 4D), when compared to the control si-NC-treated ones, respectively $(\mathrm{P}<0.05)$. Conversely, $\mathrm{p}-\mathrm{SNHG12}$ transfection significantly promoted the migration and invasion of both glioma cells (compared to the matched p-NC control, respectively) $(\mathrm{P}<0.05)$ (Fig. 4B-D).

SNHG12 inhibits the apoptosis of glioma cells. Transfection with si-SNHG12 promoted the apoptosis of either the U87
andU251 cells (compared to those transfected with si-NC, $\mathrm{P}<0.05$ ) (Fig. 5). The overexpression of SNHG12 by transfection with p-SNHG12 significantly inhibited the apoptosis of both glioma cell lines (compared to the matched p-NC control, respectively) $(\mathrm{P}<0.05)$ (Fig. 5).

SNHG12 directly interacts with HuR in glioma cells. The binding of SNHG12 with HuR was confirmed by RIP-RT-qPCR in the U87 and U251 cells. RIP assays and subsequent RT-qPCR revealed that SNHG12 was rich in RIP samples treated with HuR antibodies, when compared to the non-specific IgG antibody treated ones, which confirmed the specificity of RIP assays and RT-qPCR (Fig. 6A). RNA pull-down assays and western blot analysis also confirmed the interaction between SNHG12 and HuR (Fig. 6B). Transfection with si-HuR significantly decreased the HuR protein levels in the U87 and U251 cells 
A

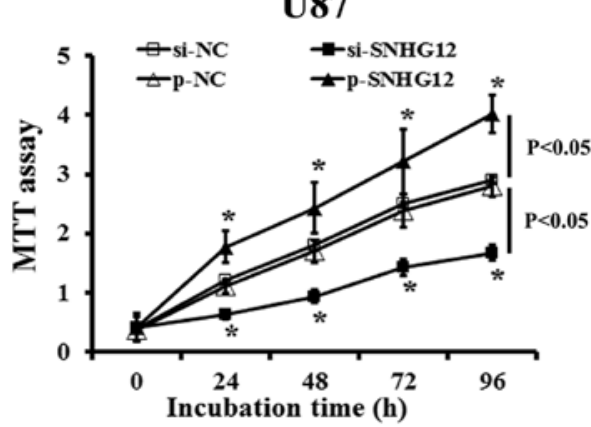

B

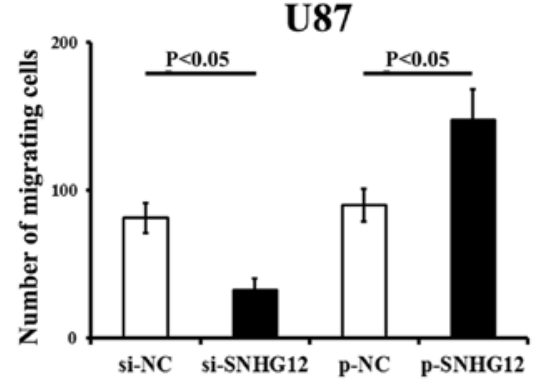

U251

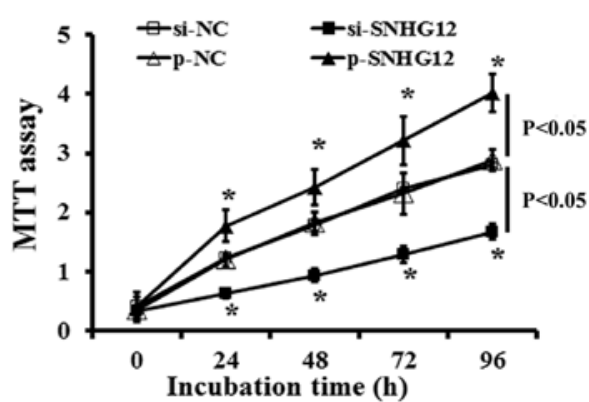

U251

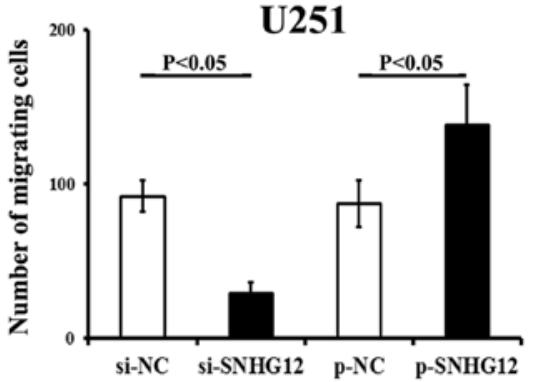

U87

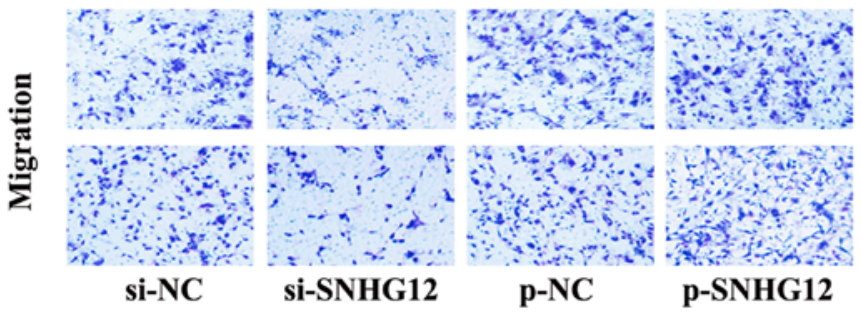

\section{U251}

U251

C
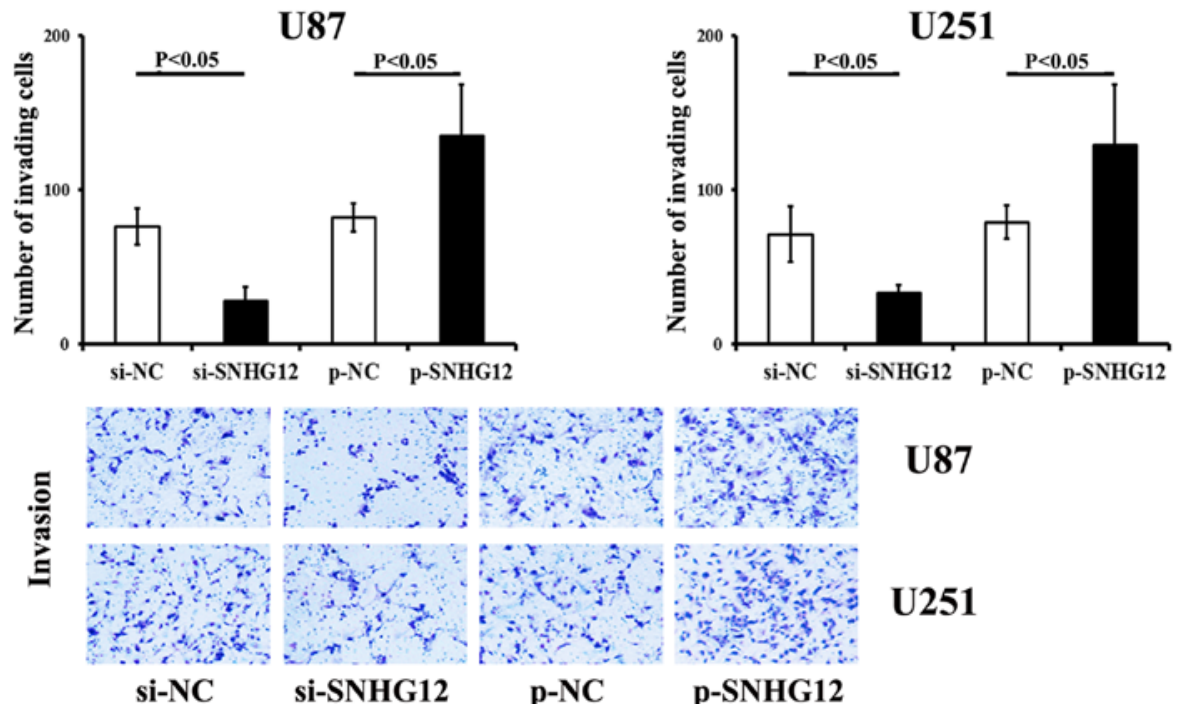

U87

\section{U251}

D

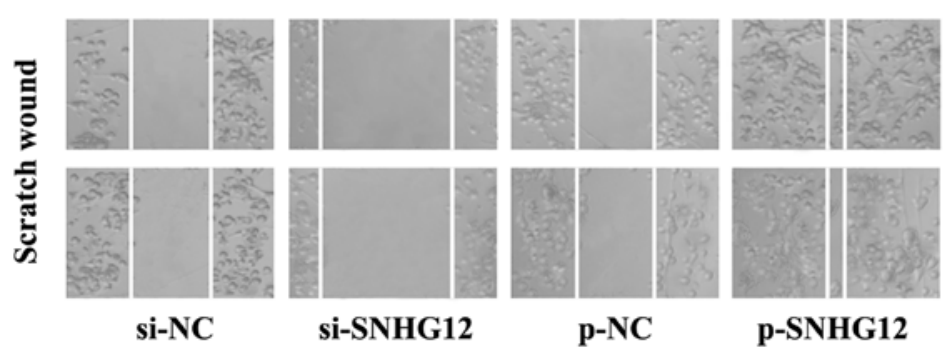

U87

U251

Figure 4. SNHG12 promotes the proliferation, migration and invasion of glioma cells. (A) MTT assay was used to evaluate cellular proliferation following transfection with siRNA and or overexpression plasmid. ${ }^{*} \mathrm{P}<0.05$ vs. matched negative control. Images and quantitative analysis of the (B) migration and (C) invasion ofU87 and U251 cells after different treatments. Stained cells were counted under random 10 fields of view by a microscope and the average cell number per view was calculated. (D) Scratch wound assay was employed to evaluate the motility of glioma U87 and U251 cells. Data are presented as the means \pm standard deviation. All data are representative of 7 independent experiments $(\mathrm{n}=7)$. si-NC, SNHG12 siRNA negative control; si-SNHG12, SNHG12 siRNA; p-NC, blank plasmid served as control; p-SNHG12, pcDNA3.1-SNHG12; SNHG12, small nucleolarRNAhost gene 12; siRNA, small interfering RNA. 

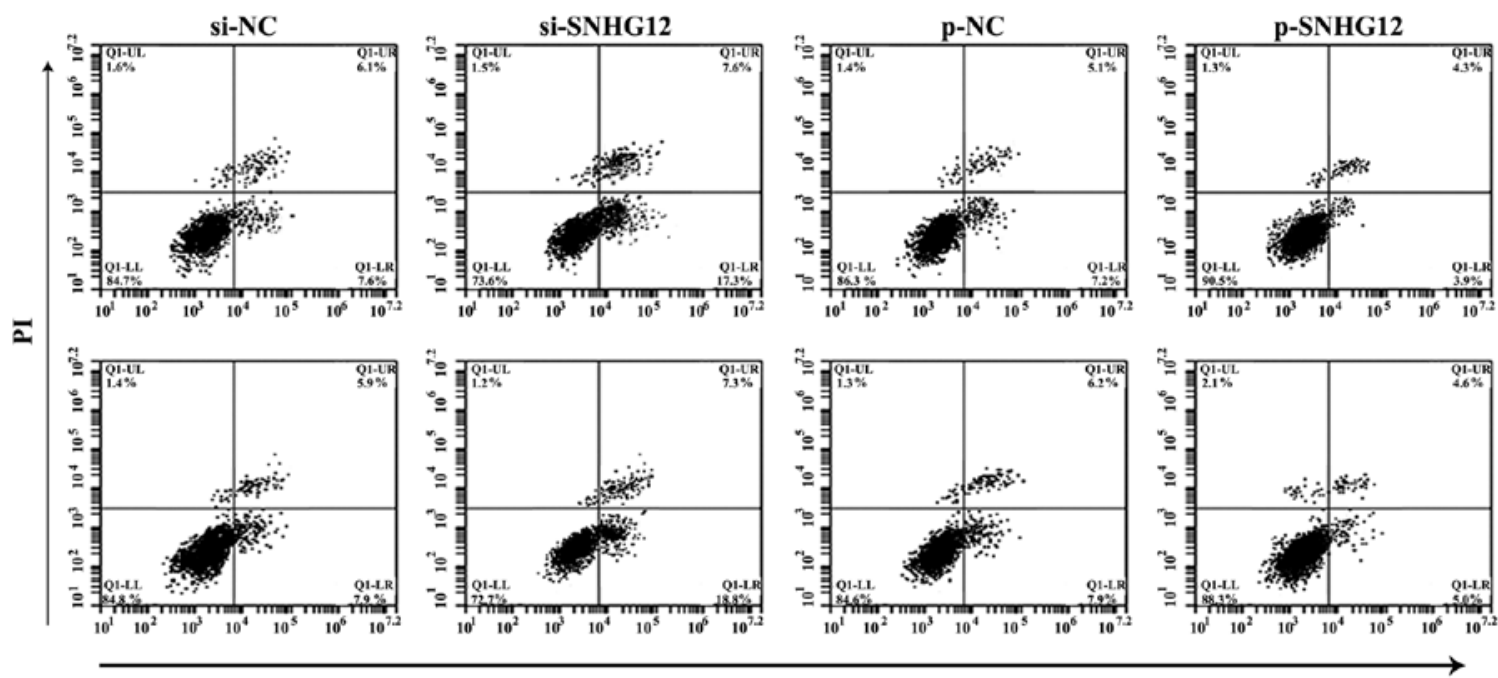

U87
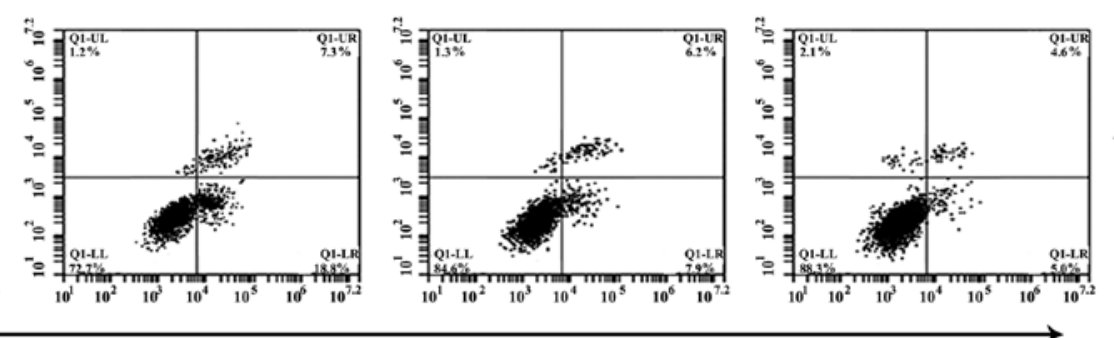

$\mathbf{U} 251$

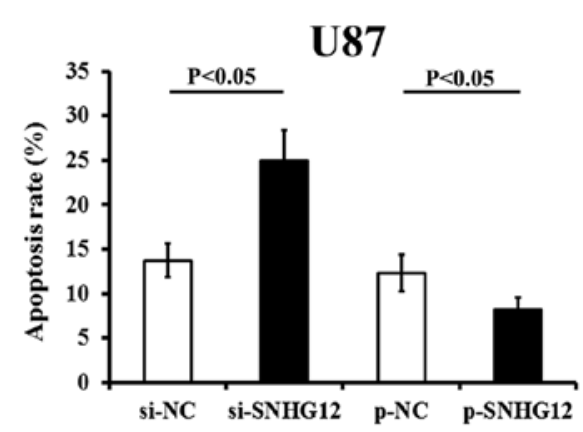

Annexin V-FITC

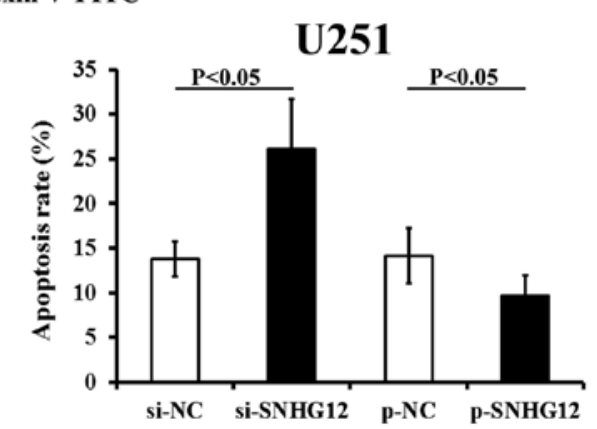

Figure 5. SNHG12 inhibits the apoptosis of glioma cells. The apoptotic rate of glioma cells following transfection with siRNA and or overexpression plasmidwas evaluated by flow cytometric analysis. Data are presented as the means \pm standard deviation. All data are representative of 7 independent experiments $(\mathrm{n}=7)$. si-NC, SNHG12 siRNA negative control; si-SNHG12, SNHG12 siRNA; p-NC, blank plasmid served as control; p-SNHG12, pcDNA3.1-SNHG12; SNHG12, small nucleolar RNA host gene 12; siRNA, small interfering RNA.

(compared to those transfected with si-NC, $\mathrm{P}<0.05$ ) (Fig. 6C). The upregulation of HuR by CMV-HuR transfection also induced an increase in HuR expression (compared to those transfected with the vector) $(\mathrm{P}<0.05)$ (Fig. 6C). Additionally, the RT-qPCR data demonstrated that the silencing of HuR expression decreased the expression of SNHG12, while the overexpression of HuR increased the level of SNHG12 in both glioma cell lines (Fig. 6D). These results revealed that SNHG12 directly bound to HuR in both U87 and U251 cells.

\section{Discussion}

The findings of the present study are the following: i) An abnormally elevated SNHG12 expression is associated with certain clinicopathological and genetic characteristics of patients with glioma; ii) patients with glioma and high levels of SNHG12 exhibit a reduced OS rate compared with those with lower levels; iii) the silencing of SNHG12 using siRNA inhibits human glioma cell proliferation, invasion and migration, and promotes apoptosis; and iv) SNHG12 interacts with HuR in glioma cells and HuR modulates the stabilization of SNHG12.

The dysregulation of IncRNAs has been demonstrated to be involved in multiple intercellular and cellular processes of numerous types of tumor (38). A novel lncRNA, SNHG12, was recently reported to be elevated in cancer and to play oncogenic roles in various types of tumor $(32,39,40)$. A previous study demonstrated that the upregulation of SNHG12 (induced by c-MYC) increased cell viability and inhibited apoptosis in triple-negative breast tumors (39). By regulating the levels of matrix metalloproteinase (MMP)13, SNHG12 was reported to be involved in cell migration in breast cancer (39). Furthermore, SNHG12 was proven to be an oncogene that contributes to the promotion of tumorigenesis and metastasis in hepatocellular carcinoma (40). However, to the best of our knowledge, there is limited information on SNHG12 in the progression of glioma. In the present study, it was found that the endogenous SNHG12 expression was significantly increased in glioma tissues and cells, while low levels of SNHG12 were associated with certain clinicopathological characteristics and the OS rate of patients with glioma. High levels of SNHG12 expression were associated with the WHO grade (III-IV) and KPS score $(<80)$, which indicated the deterioration of patients with glioma. The evaluation of the molecular genetic features of these unselected glioma cohort revealed that SNHG12 expression was also associated with the mutation of TERT and $I D H 1 / 2$, as well as with the $1 p / 19 q$ status and $M G M T$ methylated status.

The present study demonstrated that the TERT promoter mutations and IDH-wild-type are the common genotypes present in cohorts with high levels of SNHG12, which are likely to become molecular indicators associated with a poor prognosis (Table II). A previous study demonstrated that TERT promoter mutations coinciding with $I D H 1 / 2$ mutations and $1 p / 19 q$ co-deletion is the most common genotypes detected 

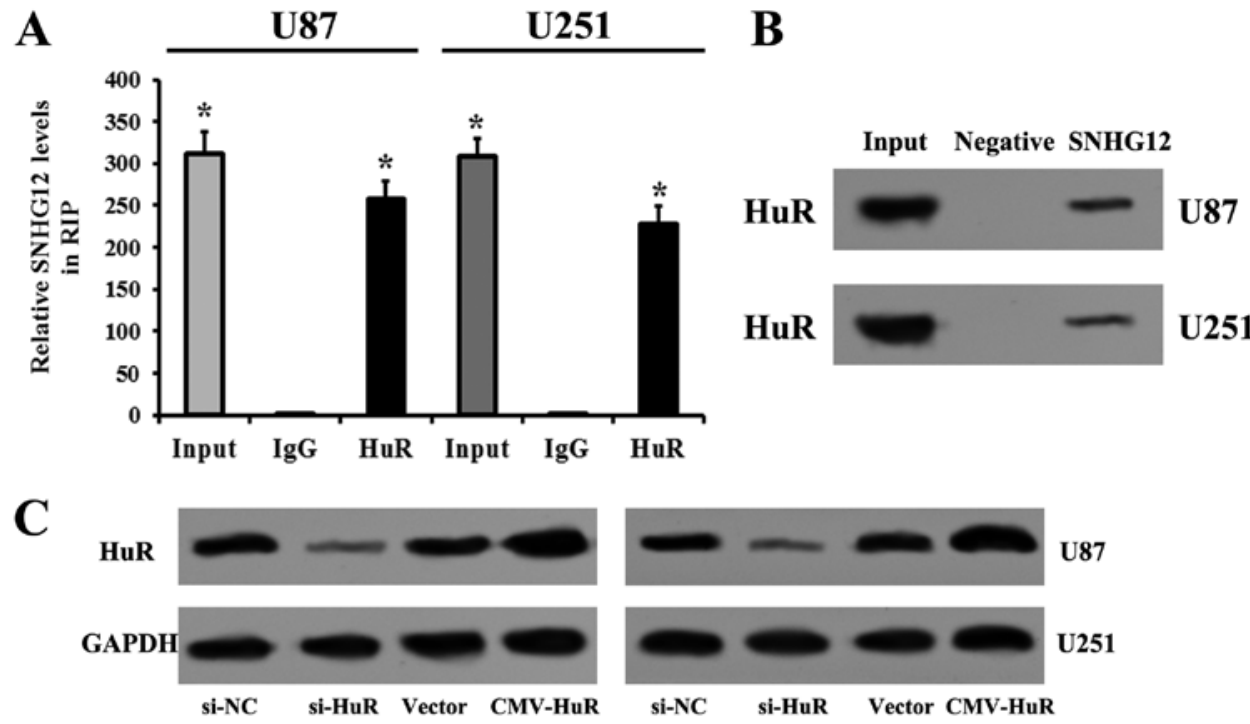

D
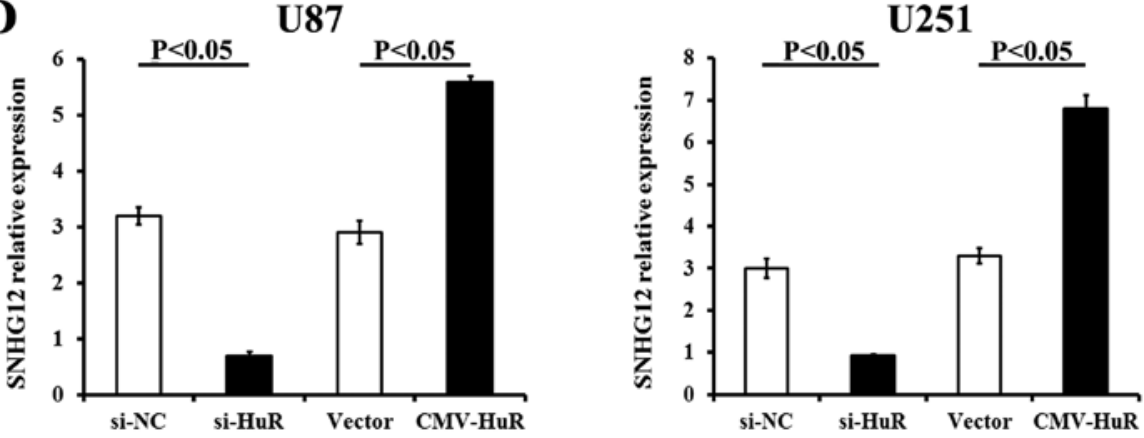

Figure 6. SNHG12 is associated with HuR in glioma cells. (A) RIP analysis was employed by using the HuR antibodies in U87 andU251 cells, followed by the RT-qPCR detection of SNHG12 expression. The expression of SNHG12 RNA was markedly enriched in HuR RIP compared to that in matched IgG control ones. ${ }^{*} \mathrm{P}<0.05$. (B) RNA pull-down assay and western blot analysis of the specific association of HuR proteins with SNHG12 revealed that biotinylated SNHG12 could bind to HuR. IgG served as a negative control, indicating the sensibility and specificity of the RNA pull-down performed. (C) HuR protein levels were detected by western blot analysis following transfection with si-HuR or CMV-HuR. (D) SNHG12 levels were evaluated, as shown by RT-qPCR following transfection with si-HuR or CMV-HuR. Values are presented as the means \pm standard deviation in 5 independent experiments. SNHG12, small nucleolar RNA host gene 12; HuR, Hu antigen R; RIP, RNA immunoprecipitation; RT-qPCR, reverse transcription-quantitative polymerase chain reaction.

in oligodendrogliomas, whereas a combined genotype of $I D H$-wild-type present and TERT promoter mutation has been observed in GBM (41). Therefore, considering the expression of SNHG12, TERT promoter and IDHI/2 mutations may be used to distinguish the subclasses of glioma and predict outcomes in high-grade glioma.

Studies have reported that the presence of IDHI/2 mutation in patients diagnosed with astrocytoma is associated with a favorable impact on survival rate $(42,43)$. These genotypes are barely observed in malignant glioma subclasses, such as primary GBM and pilocytic astrocytomas, and are usually accompanied by $M G M T$ methylation, a well-established prognostic marker for primary GBM (44-46). The present study demonstrated that the presence of $I D H 1 / 2$ mutation was positively associated with a relatively prolonged OS in patients with glioma and lower levels of SNHG12, while the presence of IDH-wild-type in those with high levels of SNHG12 was associated with a poor OS. In the unselected cohorts, the presence of MGMT methylation was detected in those with high levels of SNHG12 expression, of which many more patients were diagnosed with high grades (III-IV) (Table I). These data indicate that SNHG12 expression is highly associated with $M G M T$ methylation and the presence of $I D H I / 2$ mutation. The present study suggests that the combined assessment of SNHG12 expression and molecular characteristics may be valuable as a prognostic indicator of high-grade glioma. However, further investigations of the association between SNHG12 and the well-established molecular markers are required.

The present study demonstrated that SNHG12 may interact with HuR in the tumorigenesis of glioma cells. HuR is an ubiquitous, multi-faceted RNA-binding protein involved in the stabilization, splicing and translational regulation of mRNAs (24). HuR can enhance tumorigenesis by interaction with or regulation of the target oncogenes that encode proteins which regulate intracellular inflammation, angiogenesis, cell cycle, migration, invasion and metastasis, and chemotherapeutic sensitivity $(14,24)$. The number of potential HuR-regulated mRNAs active in these disease pathways is potentially large, as up to $8 \%$ of the transcribed genome may contain an AU-rich 3'UTR (47). In malignant GBM, HuR has been demonstrated to amplify the expression of cancer-related genes, including tumor necrosis factor (TNF)- $\alpha$, IL-8, IL-6, VEGF, cyclooxygenase (COX)2, transforming growth factor (TGF)- $\beta$ and other tumorigenic genes, which contributes to increased cell proliferation, apoptosis evasion and angiogenesis, as well as to enhanced invasion and metastasis (48-50). The totality of this 
regulation results in the necessity of glioma cells to sustain and increase growth (51). A recent study demonstrated that HuR plays crucial roles in the growth of glioma and its activity and viability were considered as potential therapeutic targets for malignant glioma (14). In the present study, RIP assays and RNA pull-down assay suggested that HuR directly interacts with SNHG12 mRNA, which contains potential AU-rich elements amenable for regulation by $\mathrm{HuR}$. The overexpressing of HuR increased the levels of SNHG12, while the suppression of HuR expression reduced the SNHG12 level in glioma cell lines. SNHG12 was significantly elevated in cohorts with glioma, while SNHG12 expressional interference inhibited viability, invasion and migration, and promoted the apoptosis of human glioma cell lines. These results suggest that SNHG12 is associated with and is stabilized by HuR in glioma cells. The HuR-SNHG12 interaction may function as an oncogenic axis and may be considered as a novel therapeutic target in glioma, particularly malignant glioma.

The present study found an elevated SNHG12 expression in tissues of patients with glioma and in glioma cells. High levels of SNHG12 were associated with certain clinicopathological characteristics and the 5-year survival rate of glioma cohorts. Interference with SNHG12 expression using transfection with specific siRNA inhibited the viability and motility, and promoted the apoptosis of human glioma cells. The data also indicated that SNHG12 was directly associated with and was stabilized by HuR. These data demonstrate that the HuR-SNHG12 axis may play an oncogenic function and may therefore could be considered as a novel therapeutic target in glioma.

\section{Acknowledgements}

The authors would like to thank Yunnan Labreal Biotechnology Co., Ltd. (Kunming, China) for their technical support.

\section{Funding}

No funding was received.

\section{Availability of data and materials}

The datasets used and analyzed in the present study are available from the corresponding author on reasonable request.

\section{Authors' contributions}

DF was responsible for the conception and design of the study. WL, ZLW and DF wrote and critically revised the manuscript. HJF, XDL and WL performed the animal experiments. WL, DF and ZLW performed the collections of specimens from patients with glioma andstatistical analysis. CZL, WL and ZLW and DF performed the cell assays, RT-qPCR, RIP and RNA pull-down assays, as well as western blot analyses. All authors have read and approved the final manuscript.

\section{Ethics approval and consent to participate}

This study complied with the Declaration of Helsinki and was approved by the Ethics Committee of Biomedicine Research, General Hospital of Shenyang Military Command
(Shenyang, China). Glioma tumor specimens were obtained from consenting patients at theGeneral Hospital of Shenyang Military Command (Shenyang, China). The patients were informed and provided written consent.

\section{Patient consent for publication}

Not applicable.

\section{Competing interests}

The authors declare that they have no competing interests.

\section{References}

1. Weller M, van den Bent M, Hopkins K, Tonn JC, Stupp R, Falini A, Cohen-Jonathan-Moyal E, Frappaz D, Henriksson R, Balana C, et al; European Association for Neuro-Oncology (EANO) Task Force on Malignant Glioma: EANO guideline for the diagnosis and treatment of anaplastic gliomas and glioblastoma. Lancet Oncol 15: e395-e403, 2014.

2. Sanai N, Polley MY, McDermott MW, Parsa AT and Berger MS: An extent of resection threshold for newly diagnosed glioblastomas. J Neurosurg 115: 3-8, 2011.

3. Stupp R, Mason WP, van den Bent MJ, Weller M, Fisher B, Taphoorn MJ, Belanger K, Brandes AA, Marosi C, Bogdahn U, et al; European Organisation for Research and Treatment of Cancer Brain Tumor and Radiotherapy Groups; National Cancer Institute of Canada Clinical Trials Group: Radiotherapy plus concomitant and adjuvant temozolomide for glioblastoma. N Engl J Med 352: 987-996, 2005.

4. Diederichs S: The four dimensions of noncoding RNA conservation. Trends Genet 30: 121-123, 2014.

5. Shi X, Sun M, Liu H, Yao Y and Song Y: Long non-coding RNAs: A new frontier in the study of human diseases. Cancer Lett 339: 159-166, 2013.

6. Huang JL, Zheng L, Hu YW and Wang Q: Characteristics of long non-coding RNA and its relation to hepatocellular carcinoma. Carcinogenesis 35: 507-514, 2014.

7. Fatica A and Bozzoni I: Long non-coding RNAs: New players in cell differentiation and development. Nat Rev Genet 15: 7-21, 2014.

8. Gupta RA, Shah N, Wang KC, Kim J, Horlings HM, Wong DJ, Tsai MC, Hung T, Argani P, Rinn JL, et al: Long non-coding RNA HOTAIR reprograms chromatin state to promote cancer metastasis. Nature 464: 1071-1076, 2010.

9. Zhai W, Li X, Wu S, Zhang Y, Pang H and Chen W: Microarray expression profile of IncRNAs and the upregulated ASLNC04080 lncRNA in human endometrial carcinoma. Int J Oncol 46: 2125-2137, 2015.

10. Ruan W, Wang P, Feng S, Xue Y and Li Y: Long non-coding RNA small nucleolar RNA host gene 12 (SNHG12) promotes cell proliferation and migration by upregulating angiomotin gene expression in human osteosarcoma cells. Tumour Biol 37: 4065-4073, 2016.

11. Gong Z, Zhang S, Zeng Z, Wu H, Yang Q, Xiong F, Shi L, Yang J, Zhang W, Zhou Y, et al: LOC401317, a p53-regulated long noncoding RNA, inhibits cell proliferation and induces apoptosis in the nasopharyngeal carcinoma cell line HNE2. PLoS One 9: e110674, 2014.

12. Iyer MK, Niknafs YS, Malik R, Singhal U, Sahu A, Hosono Y, Barrette TR, Prensner JR, Evans JR, Zhao S, et al: The landscape of long noncoding RNAs in the human transcriptome. Nat Genet 47: 199-208, 2015.

13. Brennan CM and Steitz JA: HuR and mRNA stability. Cell Mol Life Sci 58: 266-277, 2001.

14. Filippova N, Yang X, Wang Y, Gillespie GY, Langford C, King $\mathrm{PH}$, Wheeler $\mathrm{C}$ and Nabors LB: The RNA-binding protein HuR promotes glioma growth and treatment resistance. Mol Cancer Res 9: 648-659, 2011.

15. Heinonen M, Fagerholm R, Aaltonen K, Kilpivaara O, Aittomäki K, Blomqvist C, Heikkilä P, Haglund C, Nevanlinna H and Ristimäki A: Prognostic role of HuR in hereditary breast cancer. Clin Cancer Res 13: 6959-6963, 2007. 
16. Denkert C, Koch I, von Keyserlingk N, Noske A, Niesporek S, Dietel $\mathrm{M}$ and Weichert W: Expression of the ELAV-like protein HuR in human colon cancer: Association with tumor stage and cyclooxygenase-2. Mod Pathol 19: 1261-1269, 2006.

17. Erkinheimo TL, Lassus H, Sivula A, Sengupta S, Furneaux H, Hla T, Haglund C, Butzow R and Ristimäki A: Cytoplasmic HuR expression correlates with poor outcome and with cyclooxygenase 2 expression in serous ovarian carcinoma. Cancer Res 63 7591-7594, 2003

18. Costantino CL, Witkiewicz AK, Kuwano Y, Cozzitorto JA Kennedy EP, Dasgupta A, Keen JC, Yeo CJ, Gorospe M and Brody JR: The role of HuR in gemcitabine efficacy in pancreatic cancer: HuR Up-regulates the expression of the gemcitabine metabolizing enzyme deoxycytidine kinase. Cancer Res 69 4567-4572, 2009.

19. López de Silanes I, Fan J, Yang X, Zonderman AB, Potapova O, Pizer ES and Gorospe M: Role of the RNA-binding protein HuR in colon carcinogenesis. Oncogene 22: 7146-7154, 2003.

20. Heinonen M, Bono P, Narko K, Chang SH, Lundin J, Joensuu H, Furneaux H, Hla T, Haglund C and Ristimäki A: Cytoplasmic $\mathrm{HuR}$ expression is a prognostic factor in invasive ductal breast carcinoma. Cancer Res 65: 2157-2161, 2005.

21. Cho NP, Han HS, Soh Y, Lee KY and Son HJ: Cytoplasmic HuR over-expression is associated withincreased cyclooxygenase-2 expression in laryngeal squamous cell carcinomas. Pathology 39 545-550, 2007.

22. Lim SJ, Kim HJ, Kim JY, Park K and Lee CM: Expression of HuR is associated with increased cyclooxygenase-2 expression in uterine cervical carcinoma. Int J Gynecol Pathol 26: 229-234, 2007.

23. Ido K, Nakagawa T, Sakuma T, Takeuchi H, Sato $K$ and Kubota T: Expression of vascular endothelialgrowth factor-A and mRNA stability factor HuR in human astrocytic tumors. Neuropathology 28: 604-611, 2008.

24. Ortega AD, Sala S and Espinosa E: Gonzalez-Baron M and Cuezva JM: HuR and the bioenergetics signature of breast cancer: a low tumor expression of the RNA-binding protein predicts a higher risk of disease recurrence. Carcinogenesis 29: 2053-2061, 2008.

25. Louis DN, Ohgaki H, Wiestler OD, Cavenee WK, Ellison DW and Figarella-Branger D (eds): World Health Organization Histological Classification of Tumours of the Central Nervous System. International Agency for Research on Cancer, France, 2016.

26. Louis DN and Ohgaki $\mathrm{H}$ : Wiestler $\mathrm{O}$ and Cavenee W (eds): World Health Organization Histological Classification of Tumours of the Central Nervous System. International Agency for Research on Cancer, Lyon, 2007.

27. Song S, Fajol A, Tu X, Ren B and Shi S: miR-204 suppresses the development and progression of human glioblastoma by targeting ATF2. Oncotarget 7: 70058-70065, 2016

28. Arita H, Narita Y, Matsushita Y, Fukushima S, Yoshida A, Takami H, Miyakita Y, Ohno M, Shibui S and Ichimura K: Development of a robust and sensitive pyrosequencing assay for the detection of IDH1/2 mutations in gliomas. Brain Tumor Pathol 32: 22-30, 2015.

29. Arita H, Narita Y, Fukushima S, Tateishi K, Matsushita Y, Yoshida A, Miyakita Y, Ohno M, Collins VP, Kawahara N, et al: Upregulating mutations in the TERT promoter commonly occur in adult malignant gliomas and are strongly associated with total 1p19q loss. Acta Neuropathol 126: 267-276, 2013.

30. Mulholland S, Pearson DM, Hamoudi RA, Malley DS, Smith CM, Weaver JM, Jones DT, Kocialkowski S, Bäcklund LM, Collins VP, et al: MGMT CpG island is invariably methylated in adult astrocytic and oligodendroglial tumors with IDH1 or IDH2 mutations. Int J Cancer 131: 1104-1113, 2012

31. Wang XP, Shan C, Deng XL, Li LY and Ma W: Long non-coding RNA PAR5 inhibits the proliferation and progression of glioma through interaction with EZH2. Oncol Rep 38: 3177-3186, 2017.

32. Wang $\mathrm{P}$, Chen $\mathrm{D}, \mathrm{Ma} \mathrm{H}$ and Li Y: LncRNA SNHG12 contributes to multidrug resistance through activating the MAPK/Slug pathway by sponging miR-181a in non-small cell lung cancer. Oncotarget 8: 84086-84101, 2017.

33. Livak KJ and Schmittgen TD: Analysis of relative gene expression data using real-time quantitative PCR and the $2(-\Delta \Delta \mathrm{C}(\mathrm{T}))$ method. Methods 25: 402-408, 2001.
34. Wang L, Ye S, Wang J, Gu Z, Zhang Y, Zhang C and Ma X: HuR Stabilizes lnc-Sox 5 mRNA to Promote Tongue Carcinogenesis. Biochemistry (Mosc) 82: 438-445, 2017

35. Zheng J, Liu X, Xue Y, Gong W, Ma J, Xi Z, Que Z and Liu Y: TTBK 2 circular RNA promotes glioma malignancy by regulating miR-217/HNF1ß/Derlin-1 pathway. J Hematol Oncol 10: $52,2017$.

36. Liang L, Wong CM, Ying Q, Fan DN, Huang S, Ding J, Yao J, Yan M, Li J, Yao M, et al: MicroRNA-125b suppressesed human liver cancer cell proliferation and metastasis by directly targeting oncogene LIN28B2. Hepatology 52: 1731-1740, 2010.

37. He Z, Huang C, Lin G and Ye Y: siRNA-induced TRAF6 knockdown promotes the apoptosis and inhibits the invasion of human lung cancer SPC-A1 cells. Oncol Rep 35: 1933-1940, 2016.

38. Chen QN, Wei CC, Wang ZX and Sun M: Long non-coding RNAs in anti-cancer drug resistance. Oncotarget 8: 1925-1936, 2017.

39. Wang O, Yang F, Liu Y, Lv L, Ma R, Chen C, Wang J, Tan Q, Cheng Y, Xia E, et al: C-MYC-induced upregulation of lncRNA SNHG12 regulates cell proliferation, apoptosis and migration in triple-negative breast cancer. Am J Transl Res 9: 533-545, 2017.

40. Lan T, Ma W, Hong Z, Wu L, Chen X and Yuan Y: Long noncoding RNA small nucleolar RNA host gene 12 (SNHG12) promotes tumorigenesis and metastasis by targeting miR-199a/b-5p in hepatocellular carcinoma. J Exp Clin Cancer Res 36: 11, 2017.

41. Arita H, Yamasaki K, Matsushita Y, Nakamura T, Shimokawa A, Takami H, Tanaka S, Mukasa A, Shirahata M, Shimizu S, et al: A combination of TERT promoter mutation and MGMT methylation status predicts clinically relevant subgroups of newly diagnosed glioblastomas. Acta Neuropathol Commun 4: 79, 2016.

42. Turkalp Z, Karamchandani J and Das S: IDH mutation in glioma: New insights and promises for the future. JAMA Neurol 71: $1319-1325,2014$.

43. Yan H, Parsons DW, Jin G, McLendon R, Rasheed BA, Yuan W, Kos I, Batinic-Haberle I, Jones S, Riggins GJ, et al: IDH1 and IDH2 mutations in gliomas. N Engl J Med 360: 765-773, 2009.

44. Zhang YA, Ma X, Sathe A, Fujimoto J, Wistuba I, Lam S, Yatabe Y, Wang YW, Stastny V, Gao B, et al: Validation of SCT methylation as a hallmark biomarker for lung cancers. J Thorac Oncol 11: 346-360, 2016.

45. Malmström A, Grønberg BH, Marosi C, Stupp R, Frappaz D, Schultz H, Abacioglu U, Tavelin B, Lhermitte B, Hegi ME, et al; Nordic Clinical Brain Tumour Study Group (NCBTSG): Temozolomide versus standard 6-week radiotherapy versus hypofractionated radiotherapy in patients older than 60 years with glioblastoma: The Nordic randomised, phase 3 trial. Lancet Oncol 13: 916-926, 2012.

46. Wick W, Platten M, Meisner C, Felsberg J, Tabatabai G, Simon M, Nikkhah G, Papsdorf K, Steinbach JP, Sabel M, et al; NOA-08 Study Group of Neuro-oncology Working Group (NOA) of German Cancer Society: Temozolomide chemotherapy alone versus radiotherapy alone for malignant astrocytoma in the elderly: The NOA-08 randomised, phase 3 trial. Lancet Oncol 13: 707-715, 2012.

47. Bakheet T, Williams BR and Khabar KS: ARED 3.0: The large and diverse AU-rich transcriptome. Nucleic Acids Res 34: D111-D114, 2006.

48. Katsanou V, Milatos S, Yiakouvaki A, Sgantzis N, Kotsoni A, Alexiou M, Harokopos V, Aidinis V, Hemberger $M$ and Kontoyiannis DL: The RNA-binding protein Elavl1/HuR is essential for placental branching morphogenesis and embryonic development. Mol Cell Biol 29: 2762-2776, 2009.

49. Katsanou V, Papadaki O, Milatos S, Blackshear PJ, Anderson P, Kollias G and Kontoyiannis DL: HuR as a negative posttranscriptional modulator in inflammation. Mol Cell 19: 777-789, 2005.

50. Streffer JR, Rimner A, Rieger J, Naumann U, Rodemann HP and Weller M: BCL-2 family proteins modulate radiosensitivity in human malignant glioma cells. J Neurooncol 56: 43-49, 2002

51. BolognaniF,Gallani AI,Sokol L, Baskin DS and Meisner-Kober N: mRNA stability alterations mediated by HuR are necessary to sustain the fast growth of glioma cells. J Neurooncol 106 : 531-542, 2012. 